\title{
Generic Modeling and Configuration Management in Product Lifecycle Management
}

\author{
Souheil Zina, Muriel Lombard, Luc Lossent, Charles Henriot
}

\begin{abstract}
The PLM (Product Lifecycle Management) is often defined as a set of functions and procedures which allows one to manage and to exploit the data defining at the same time the products and the processes implemented for their developments. However, the installation of a PLM solution remains a difficult exercise taking into account the complexity and the diversity of the customer requirements as well as the transverse utilization of this solution in all the company's' functions. The issues faced by both editors and integrators of PLM applications arise from the specific aspect of customers' projects, even tough most functional needs are often generic.

In this paper we are focused on product modeling in PLM applications, more particularly on configuration management that traces product evolutions throughout its lifecycle. we will insist on the links between the configuration needs and the multi-view approach models and we release problems related to PLM applications deployment. Our work concerns the PLM generic solutions based on the concept of generic models. This generic model takes into account the configurations specification associated to the managed product and can be extended to cover specific needs.
\end{abstract}

Keywords: PLM, Configuration management, Generic modeling.

\section{Introduction}

Monitoring the technical information is one of the main preoccupation of the companies. Indeed, the increasingly constraining regulations and the higher competition level require being more rigorous and reactive to the customers' requests. The product quality improvement and the reduction costs cycles require applying technical data management rules and means.

The PLM (Product Lifecycle Management) appeared to answer the need of managing growing volumes of data in more and more complex environments. The PLM covers product life cycle integrality, without stopping itself at the design stages; it extends today to a wide scope of fields such as the Aerospace-Defense, Food, Drugs, Public Sector, Engineering, Manufacturing, etc. Product term thus indicates diverse entities in very varied trades.

The product life cycle management by a PLM solution allows including, not only all the necessary elements to ensure its traceability, like modeling, document management, numerical analysis, know-how capitalization, etc. but all the information system components making it possible to ensure the product monitoring from its manufacture to its marketing until its disappearance or likely its recycling.

In PLM applications, the technical data are organized within configurations. The configuration management is used to manage products complexity and knowledge diversity resulting from various business cases in the company. Indeed, the growing number of PLM applications users, the technical data volume and the various evolutions associated to these data require:

- controlling and checking the exchanged technical data consistency, unicity and safety,

- taking into account data evolutions and all their effects on the product and its components. 
This is why the configuration management is a fundamental component in PLM applications, making it possible to control and manage complexity related to the data.

In the literature, several researches treat various types of problems around the PLM. This work is especially interested in the problems related to the data exchange and sharing [32, 26], the process management problems $[19,12,33]$ and the product configuration management problems $[20,21,18,4]$.

In this paper, we are centered on technical data management and particularly on configuration management. In the first part of this document, we present problems related to the configurations modeling and a treatment example on given configurations. In the second part, we will show why the PLM solution deployment in a company remains a difficult exercise with the showing off of first problems.

The study carried out at LASCOM ${ }^{1}$ consisted, starting from existing PLM applications, to set up a step of reverse engineering which made it possible to formalize the concepts used in PLM applications within a UML meta-model. This fundamental stage made it possible to validate the handled concepts at the conceptual level, then to underline the advantages of working on this modeling level to capitalization.

\section{The product modeling in PLM applications}

A technical object is thus a business object on which data management requirements are expressed in regard to the management and the handling of complex objects. The technical data concerns the design, the manufacture, the maintenance, the recycling and the marketing [3]. The definition of various business or technical objects and the links between them strongly depends on the company needs, organization and working methods.

The diversity of PLM applications (diversity related to the customer's specificities), the data increasing complexity and the need for evolving and flexible systems (due to the evolution of the needs as time goes by) implies that there is not an universal PLM application model being able to meet all the customers conflicting needs.

In the literature several research tasks are interested in product modeling with different approaches and technologies: use RDF (Resource Description Framework) [17], Topic Maps [16], or the orientedobject approaches [9] which aim to model and implement PDM (Product Data Management) systems using UML (Unified Modeling Language).

\subsection{Configuration Management in PLM applications}

Research works are interested in methods and tools development for managing the product configuration; they deal especially with generic product modeling. In the literature, several methods, based on artificial intelligence techniques, propose solutions to solve the products configuration problems [29]. These methods are based on rules and constraints $[1,31,10]$.

The product configuration is based on a configuration model (often called product generic structure); the model describes the components (called also configuration elements or objects members of a configuration) that can be included in the product configuration. The configuration model also includes the combination rules between these components.

Various tools, called configurators (e.g. EngCon [14], WeCoTin [2]), make it possible to obtain a precise product description, which satisfies the needs and which is validated by the compliance with the rules of constraints defined in the configuration model. These tools can be integrated in PLM applications to

\footnotetext{
${ }^{1}$ LASCOM (www.lascom.com) is an editor of life cycle management solutions concerning company product and processes.
} 
contribute to configure the product.

In our work we are centered particularly on the configuration management. Like configuration tools, the configuration management tools are also based on product models making it possible to formalize technical objects, links and constraints which express managed and traced needs. Indeed, the configuration management is a discipline of management which consists in applying technical and administrative rules to the development, the production and maintenance, in all configuration article life cycle. It consists in managing the technical description of a system (and its different components), like managing the whole of the modifications made during the system evolution.

The configuration management finds out an interest when it concerns a product management that have a lot of variants and a long lifecycles or unit complex products like the production system itself or special machines [22]. Figure 1 presents a configuration example of a production site composition modeled in a PLM application. This configuration follow the evolution of the productions lines and their adaptability to the product.

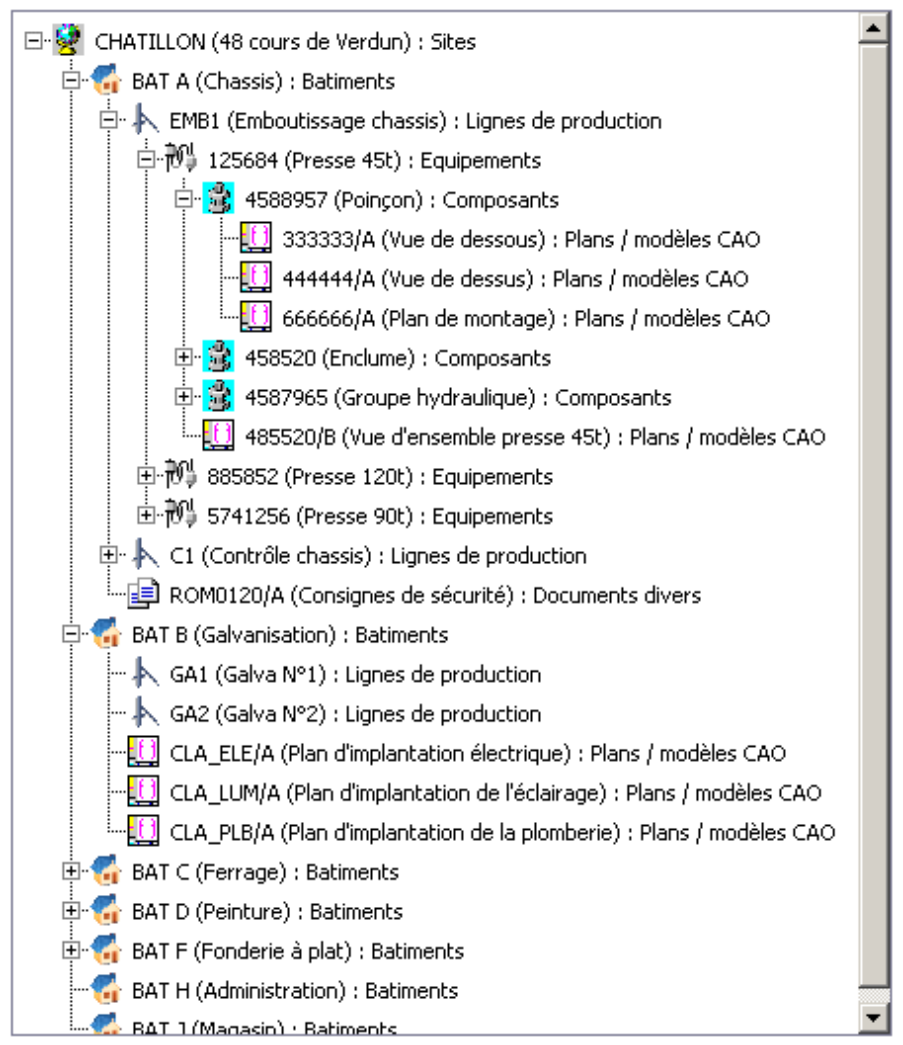

Figure 1: Example of a production site configuration.

The configuration management consists in controlling information of product structure, especially its decomposition in elementary subsets, parts and addition to the whole of this information, functional and physics characteristics. The standard [15] presents recommendations for using configuration management in industry. It provides the detailed process, organization and procedures of management. According to this standard, the configuration management is an integral part of the PLM; it provides a clear vision of the configuration state, associated to products or projects, as well as theirs evolutions by guaranteeing a total traceability.

Configuration management tools integrate functions and mechanisms allowing audit and control of all actions carried out on the product configuration. 


\subsection{Product multi-point of view modeling}

The concepts of view and point of view were studied in several fields related to the data processing: databases, analyzes and design, programming languages, etc. In the literature several research tasks integrated the concepts of view and point of view in products modeling [24, 23, 13, 25, 28], these views are generally used to express different trades' needs on the product. Figure 2 presents an example of different business views around a product.

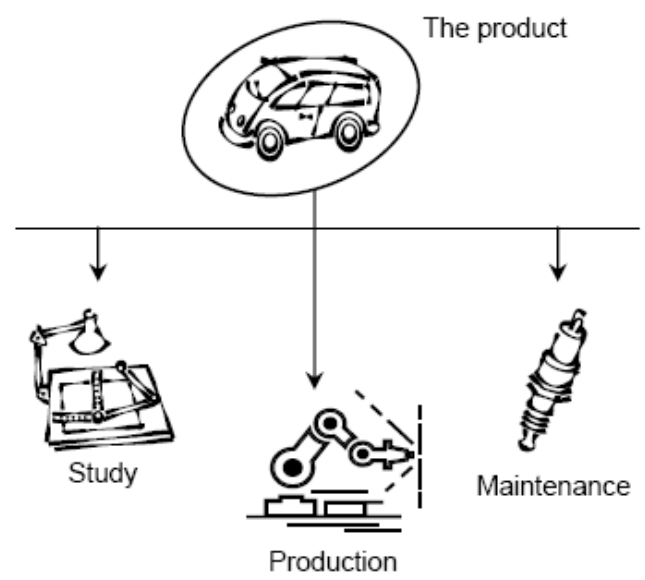

Figure 2: Various business views associated with a product.

The notion of point of view, classically used in the literature, has for main goal the description of a complex entity having several facets. The points of view make it possible to structure information starting from various criteria related with trade or product. This make it more representative and understandable and so easier to exploit. Each actor of the company handles particular view of the product that corresponds to his specific needs: functional view, technical view, industrial view, etc.

There are two principal approaches which were used to take into account the actors points of view in the product model: Multi-view and Multi-model approaches.

The multi-view approach is based on the development of a single model starting from different views. This unique model is accessible according to several points of view. The main advantage of the use of a single model is that modifications made on a sub-model are reflected in the other sub-models. Consequently, the problems of inconsistency due to the division of the data between the partial models are avoided [24, 23]. This approach is very much used in works to product representation in CAD (Computer-Aided Design) systems. Research of Million [23] relates to the problem of designing technical information systems in an industrial multi-actors context in order to visualize information according to various views. The suggested method, called VIM (Viewpoints Information Modeling), makes it possible to build up, by successive adjustments, a total data model starting from an initial model centered on the technical object according to the points of view considered.

The principal interest of the multi-view approach lies in the fact that there is a unique model to manage, which facilitates the exchanges management and information sharing. However, it leads to a static product representation because the models handled by the various actors are fixed and do not vary at the same time as the product representation [8].

The multi-model approach consists in creating a model associated with each actor's view on the 
product. Thus, there as exist many models as of different points of view on the product. Each model contains the technical objects and the relations which correspond to the given point of view. The management of the relations between these various models imposes using a whole of coherence rules which must apply to the models whole.

The Multi-models approach makes possible to structure the data following specific models to each point of view on the product. These separated models can evolve independently. However, coherence maintenance and information sharing between these models are much more difficult to ensure. The problem of coherence is attenuated by the use of rules of coherence, but their identification and their formalization remain difficult.

\subsection{Configuration models and data processing}

To be coherent with the different actors needs on the product, the configuration models must take into account these concepts of view and points of view associated to the product. According to the application needs, Advitium ${ }^{\mathrm{TM}}$, software package developed by the LASCOM company, define several types of configuration for a product (a given technical object). We define, for example, design configuration, documentary configuration, configuration carried out according to the stages reached in the project, etc. These configuration types correspond to different points of view on the product.

Each configuration is based on its own model and can evolve independently of the other types of configuration associated with the product. These configurations structure the data necessary to the product definition. Thus, each actor will gather, treat on a hierarchical basis and complete the technical objects according to his own needs. It is for this purpose that various structures of the product are managed. Each one corresponds to a particular configuration type.

We defined the concept of "context" related to the configuration elements in order to take into account the specific use of context data. The application of a context allows defining contextual views on the configuration [34].

Starting from existing PLM applications, the study carried out at LASCOM consisted in setting a step of reverse engineering (step 1) which made it possible to formalize the concepts (step $2 \& 3$ ) used in Advitium ${ }^{\mathrm{TM}}$ within an UML meta-model [27] (this meta-model is not presented in this paper). The employed methodology is illustrated by figure 3, the PLM applications deployment (step 4 \& 5) is described by figure 7 section 3.1. 


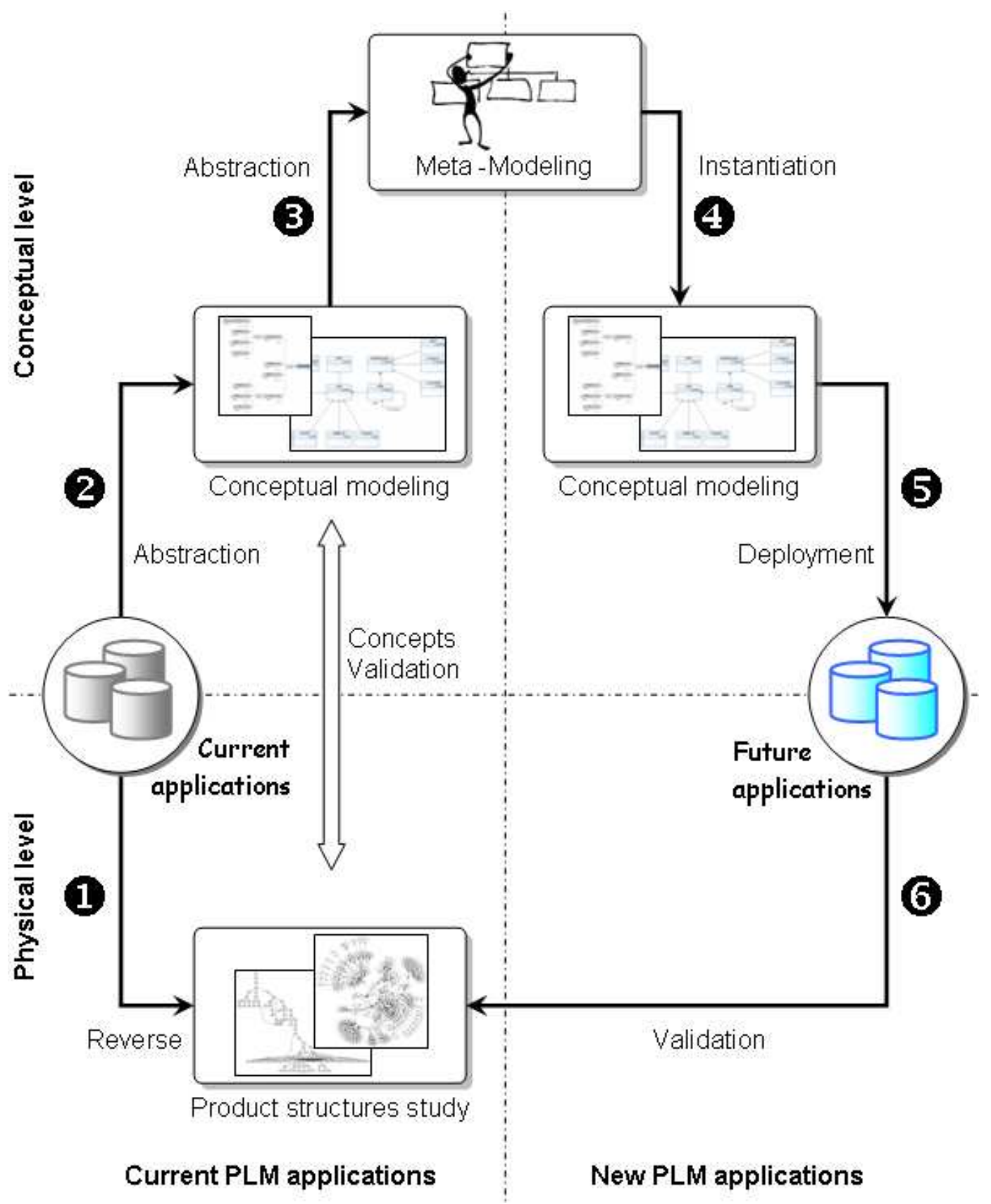

Figure 3: The employed methodology.

We developed tools for PLM applications retro-modeling, these tools allow formalizing configuration links between various technical objects classes. Our problematic is located in the formalization of the technical objects and links existing between them to answer:

- a technical data presentation matter to user,

- optimization of existing links in data base considering semantic studies produced according to customers requirements,

- easy access to configuration data and an optimization of the treatments on the configuration elements. 
Our tool allows, from Advitium ${ }^{\mathrm{TM}}$ relational databases, to generate an XSD (Xml Schema Definition) of configurations definition. Figure 4 represents the hierarchical structure of classes in an example of a technical object (OT01_SITE) configuration model. An example of this class instance is given by figure 1.

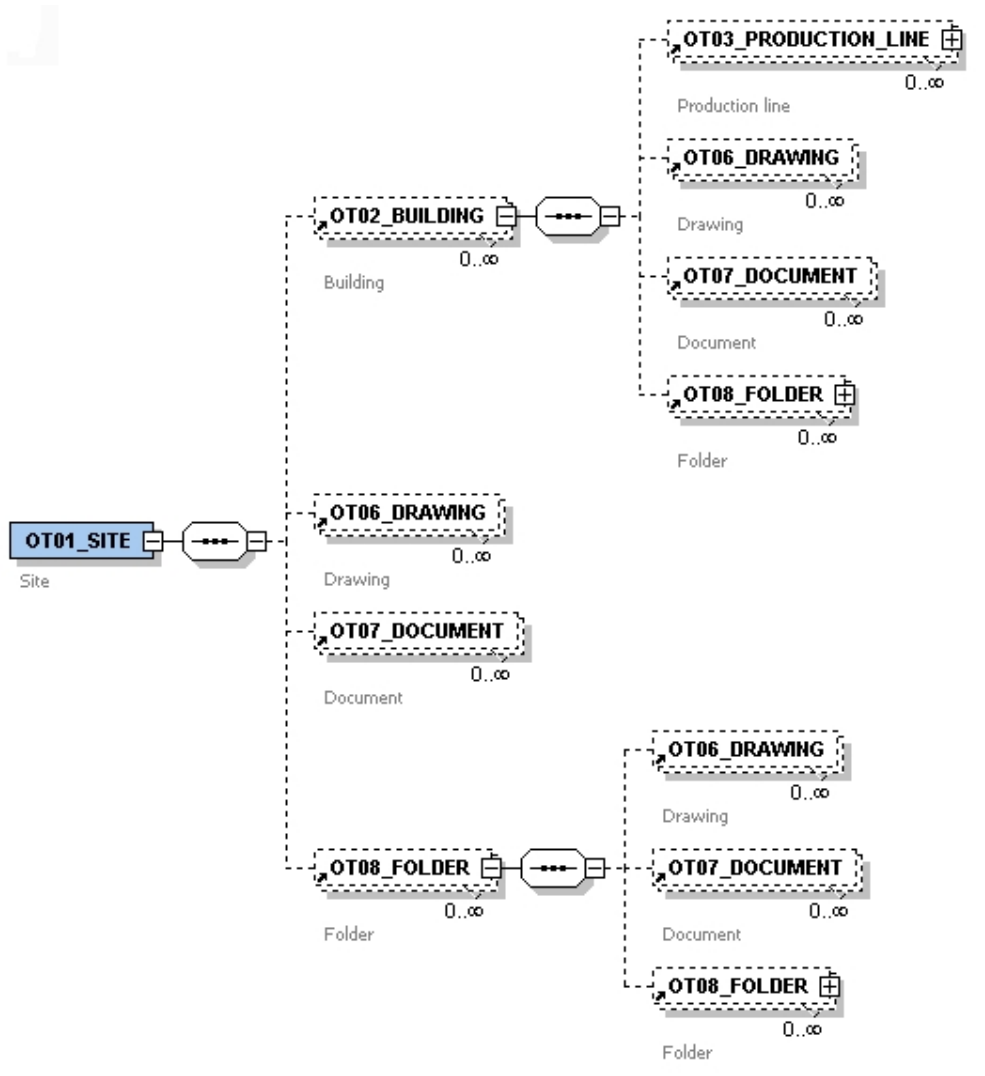

Figure 4: Example of configuration XML Schema.

In this model, configuration elements (Buildings, Drawings, Documents, Folders, etc.) are linked between them and organized to form configurations.

Technical objects can be related for various reasons: to express a composition link, to make a specialization, membership, etc. Links between the technical objects can be static (specific to a technical object instance) or dynamic (evolve with the technique objects versions) [4]. Majority of configuration models are recursive. It is noted, in figure 4, that the class "Folder" is re-used at various places in the hierarchy. This led, at the physical level, to infinite hierarchical structures. Our tool, associated with Graphviz [11], allows the visualization of configuration links graph of an existing PLM application. This representation informs us about the configuration structure and characteristics (depth, degree of objects re-uses, etc.).

Figure 5 presents the graph of product study configuration. We noted that the whole of the technical objects which constitute the product structure can be represented using a DAG (Directed Acyclic Graph). Each graph consists of nodes set (technical objects); these nodes are connected by links. Links have properties (link type, beginning and expired dates, etc.) allowing to describe more precisely relationships among the objects and authorizing, thus, the configuration traceability evolutions. 


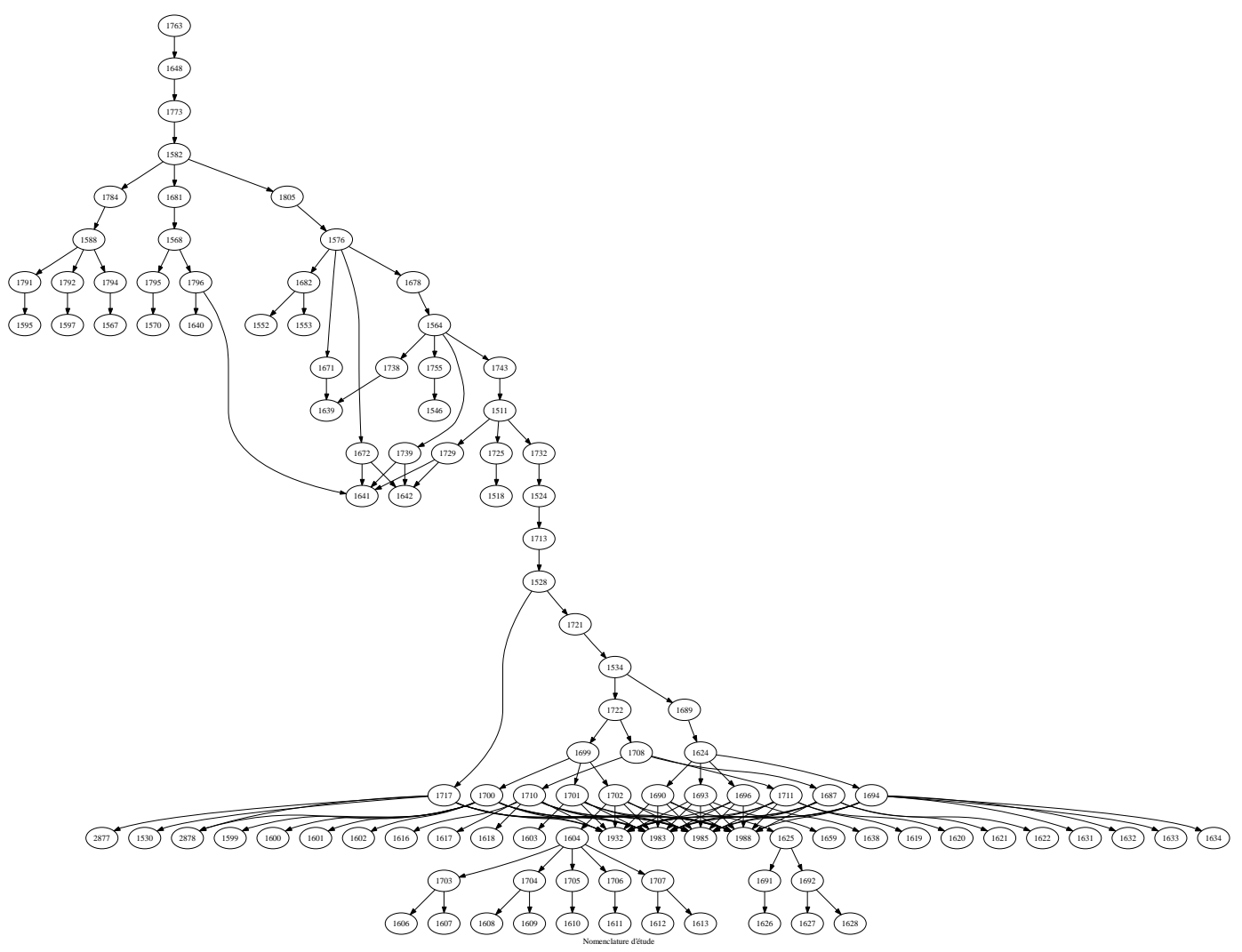

Figure 5: Example of study configuration graph in existing PLM applications.

The nodes can contain additional informations (order, descriptions, etc.), which lead the need for defining an entity node as presented at figure 6 .

In order to implement applications according to customer requirements, this model includes a set of basic concepts (figure 6.a) independent of any applicability use (e.g. Part, Configuration, User, Group, etc.). These concepts can be specialized to complet the model according to application needs (figure 6.b). The derivation of this conceptual model gives a part of the physical model (relational model) currently implemented in the Advitium ${ }^{\mathrm{TM}}$ software package.

Data treatments related to the configurations can be inspired from techniques and methods resulting from the graphs theories. Indeed, in the configurations handling and management, certain basic user's functions are commonly used:

- Search, in a given technical object configuration, the whole of descendants of this object (to obtain the configuration elements).

- Search, in a given technical object configuration, the whole of the ascending of this object (to obtain the employment cases).

- Make search with criteria related on technical objects and their links properties (e.g. validity dates). In certain research, the criteria on links properties must be checked for the whole links constitute the way between the starting and arrival technical object.

In order to improve application performances related to configurations management (in particular search and navigation functions in configurations), we studied certain technical solutions which aim im- 


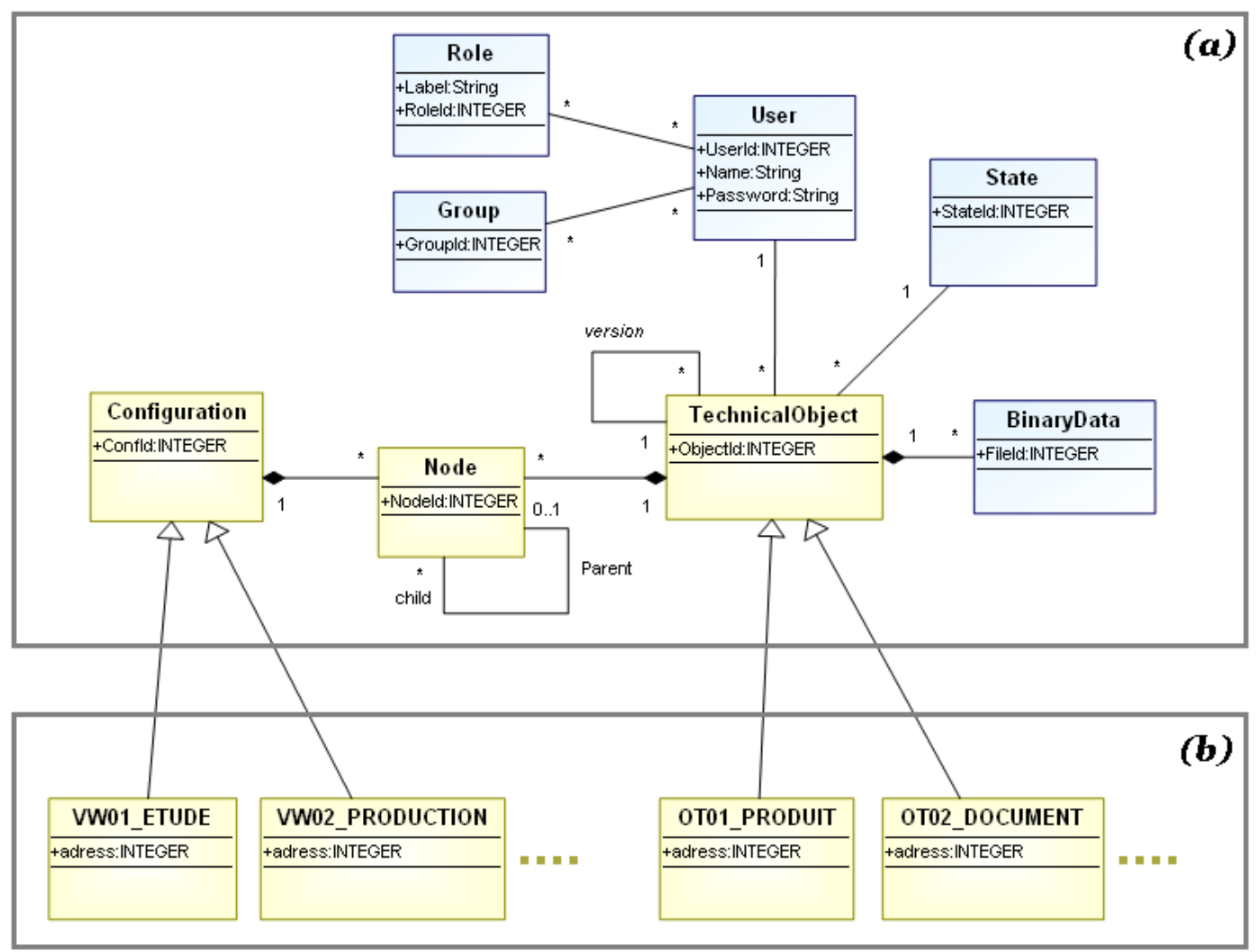

Figure 6: A part of generic model.

plementing hierarchical structures in relational databases. Among these solutions, we quote the "Nested Sets" method [5] (well adapted to handle the trees structures in the relational databases). Other research tasks are interested in the resolution of this problems type which consists in managing hierarchical data structures in relational databases [7, 30].

\section{The reference model construction}

PLM applications are based on complex and evolving product structures. The issues faced by both editors and integrators arise from the specific aspect of customers' projects. As company's needs are often specific, a PLM solution implementation requires heavy investments mainly regarding development aspects. These developments require huge implementation timetables and massive resources. One explanation lays on the fact that developments are very specific, and stress applied by PLM solution integrators on physical aspect rather than on conceptual aspect.

However, the consideration of the needs at the conceptual level, by PLM applications editors, permit to capitalize knowledge related to their products engineering and to rationalize the design and development teams working methods. Indeed, the knowledge capitalization helps to preserve, to share and above all to re-use know-hows generated through customers' projects. This re-use thus allows:

- offering a better times control of engineering and a more flexible software offer,

- limiting PLM applications maintenance costs,

- facilitating the evolution PLM applications and allowing a greater users autonomy. 


\subsection{The generic models}

So as to capitalize, it is recommended to study a set of reference models by sector or trade, in order to have a base of standard models or generic models. In fact, it is rather easier to particularize a model dedicated to a sector of activity than to reinvent it each time.

Thereby, we reveal two levels of trade:

- Generic level: in this level a person is in charge of creating generic models, by studying certain number of similar cases already encountered and modeled in reference models. These models can be enriched, if necessary, with generic specificities even if these specificities are not used till now but they are useful regarding the preceding businesses.

- Particular level: in this level a person is particularizing this generic level suited to trade to obtain the particular desired model. This model is particularized according to the specification elements. Thus, this person will have to particularize a partially defined model existing, and will have only to complete this initial model so as to provide the model to be implemented in the company, consequently making a gain of time.

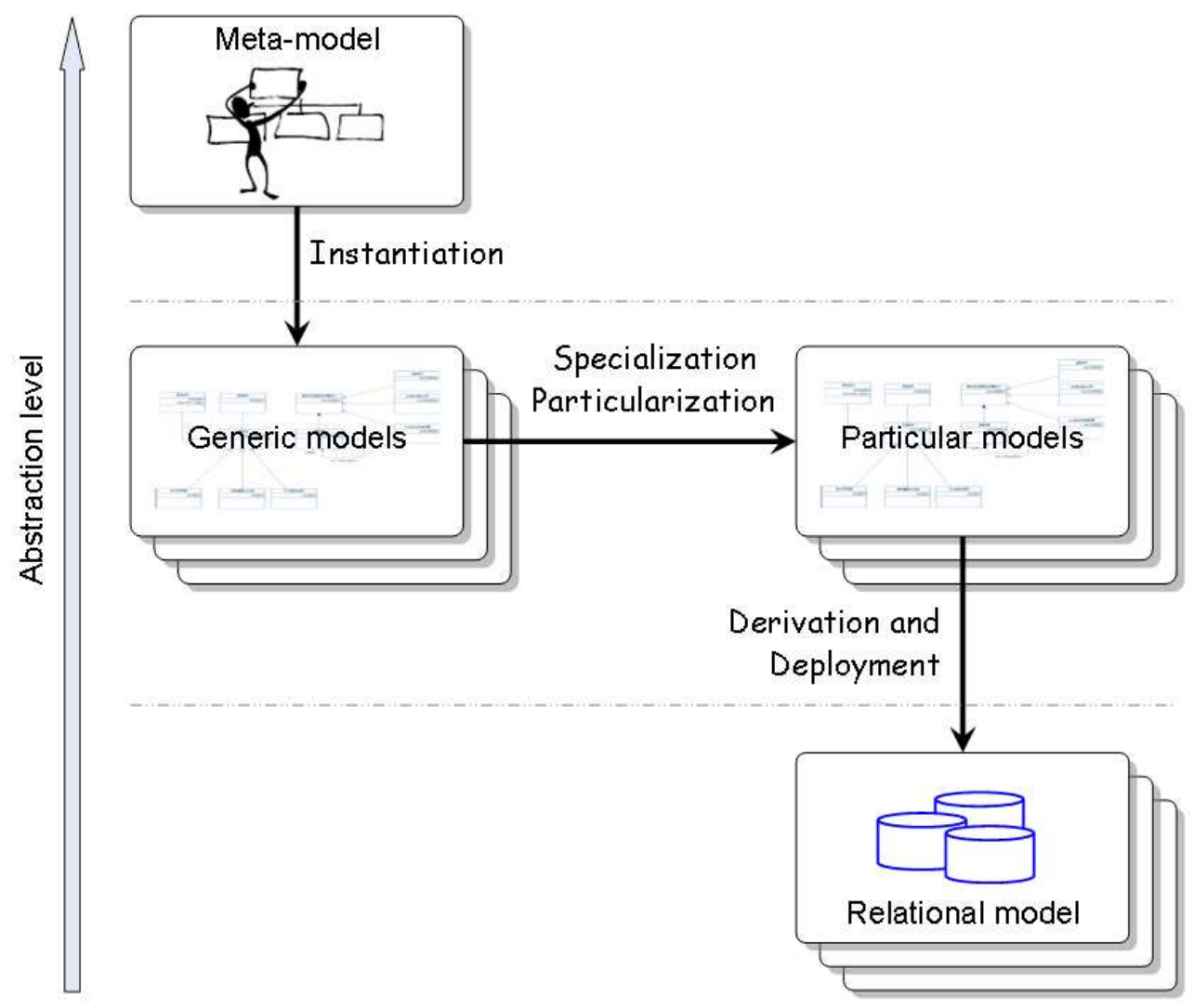

Figure 7: Process of model instantiation.

Figure 7 represents the interest that can be disposed by generic models per activity sector to simplify the work of PLM solutions integrators or developer.

\subsection{Functions deployment}

It has already been showed, compared to database modeling approaches, that a good data organization (coherent models and adapted to the needs) allows to considerably simplify the treatments and 
thus to improve the performances of the concerned applications. Indeed, a generic implementation is often too general when it is used in a specific situation; this generalization often causes an ineffective execution. To increase the performances, this implementation must be adapted in order to keep preserving only the necessary functionalities in a specific situation.

It is thus suitable to define and associate elementary functions to the generic models. These functions can be combined and organized to meet the specific needs expressed during models particularization. Otherwise, for better PLM application appropriation by users, a "trade translation" of the functions is also necessary.

\section{Summary and Conclusions}

The product life cycle management is a recent field, the perimeter of PLM applications is in constant evolution. This evolution implies that there is not a data model able to meet all the customer requirements.

Our work concerns the generic solutions of technical data management based on the concept of generic model. This generic model takes into account the configuration specification associated to technical objects.

Disposing of generic models by sector or by trade permits to facilitate the work of the PLM solutions integrators or developers. This work can be done through an audit to extract the modeling invariants. It is advisable to well determine the trade sectors. Thus, in the objective of the PLM tools appropriation by the users, this classification propose solutions practically ready-made for its deployment in term of modeling of the technical data. This dimension allows decreasing or eliminating the specific developments. In these models, the terminology thus is well taken into account, since particularized with a given industrial sector.

\section{References}

[1] M. Aldanondo, H. Fargier, and M. Véron. Configuration, configurateurs et gestion de production, Hermès Science, Traité IC2 Productique, pp.179-209, 2001.

[2] T. Asikainen,T. Männistö, and T. Soininen. Using a Configurator for Modelling and Configuring Software Product Lines Based on Feature Models, WSVMPD, 2004.

[3] A. Bernard. Modèles et approches pour la conception et la production intégrées. Productique, méthodes et outils, CPI'99, numéro spécial de la revue JESA, Vol.37, Issue 2-3, 2000.

[4] T. W. Carnduff and J. S. Goonetillake, Configuration management in evolutionary engineering design using versioning and integrity constraints, Advances in Engineering Software, Vol.35, Issue 3-4, pp.161-177, 2004.

[5] J. CELKO. Joe Celko's Trees and Hierarchies in SQL for Smarties. Morgan Kaufmann, 2004.

[6] P.Y. Chao and T.D. Chen. Analysis of Assembly through Product Configuration, Computers in Industry, Vol.44, pp.189-203, 2001.

[7] Y. Chen, On the computation of recursion in relational databases. In Effective Databases For Text \& Document Management, S. A. Becker, Ed. Idea Group Publishing, Hershey, PA, pp.263-277, 2003. 
[8] I. El Khalkhali. Système intégré pour la modélisation, l'échange et le partage des données de produits. Institut National des Sciences Appliquées de Lyon, 2002.

[9] B. Eynard, T. Gallet, P. Nowak, and L. Roucoules. UML based Specifications of PDM Product Structure and Workflow. Computers in industry, Vol.55, Issue 3, pp. 301-316, 2004.

[10] H. Fargierh and L. Henocqueh. Configuration à base de contraintes. Information Interaction Intelligence, Actes des 2ième Assises nationales du GdR I3, pp.141-159.

[11] AT\&T Labs, 2005. Graphviz.

Available from: http://www.research.att.com/sw/tools/graphviz/.

[12] D. Grigori, F. Casati, M. Castellanos, U. Dayal, M. Sayal, and M.-C. Shan. Business Process Intelligence, Computers in Industry Journal, special issue on workflow mining, Vol.53, Issue 3, pp.321343, 2004.

[13] Y. Harani. Une approche multi-modèles pour la capitalisation des connaissances dans le domaine de la conception. $\mathrm{PhD}$ thesis, Institut National Polytechnique de Grenoble, 1997.

[14] O. Hollmann, T. Wagner and A. Günter. EngCon Ü A Flexible Domain-Independent Configuration Engine. Workshop Configuration at ECAI-2000, 2000.

[15] ISO 10007:2003. Quality management systems Û Guidelines for configuration management, 2003.

[16] ISO/IEC 13250:2003. Information technology - SGML applications - Topic maps (2nd edition), 2003.

[17] H-B. Jun, D. Kiritsis, and P. Xirouchakis. Product lifecycle information modeling with RDF, International Conference on Product Lifecycle Management, pp.44-54, 2005.

[18] E. Kasper and J. Riis. Expected and Realized Costs and Benefits when Implementing Product Configuration Systems, International Design Conference - Design 2004, Dubrovnik, Croatia, 2004.

[19] A K A de Medeiros, WMP van der Aalst, AJMM Weijters. workflow mining: current status and futur directions. Coops/DOA/ADBASE, LNCS 2888, pp.389-406, 2003.

[20] T. Männistö, R. Sulonen. Evolution of Schema and Individuals of Configurable Products, in Proc. of ECDM'99 - Workshop on Evolution and Change in Data Management, Versailles, France, Springer Verlag, November 15-18, 1999.

[21] T. Männistö. A conceptual modelling approach to product families and their evolution. $\mathrm{PhD}$ thesis, Helsinki University of Technology, 2000.

[22] P. Martin, L. Lossent, L. Abt and F. Brasset. Conception de machines spéciales: méthodologie d'élaboration de cahier des charges. Mécanique \& Industries Vol.5, pp.305-316, 2003.

[23] O. Million, M. Lombard, G. Ris. Analysis and modeling of a technical information system: A modular approach. Proceedings of IDMME'1998 Integrated Design and Manufacturing in Mechanical Engineering, UTC, Compiégne (France), Vol.4, pp.1245-1252, May 27-29, 1998.

[24] M. Nassar. VUML: A Viewpoint oriented UML Extension. In the 18th IEEE International Conference on Automated Software Engineering (ASE’2003), Montreal, Canada, 2003.

[25] F. Nöel. A Dynamic multi-view product model to share the product behaviours among designers. International Conference on Product Lifecycle Management, pp.113-120, 2005. 
[26] P. Nowak, B. Rose, L. Saint-Marc, B. Eynard, L. Gzara, M. Lombard. Towards a design process model enabling the integration of product, process and organisation, 5th International Conference on Integrated Design and Manufacturing in Mechanical Engineering, IDMME 2004, Bath (United Kingdom), April 5-7, 2004.

[27] OMG. OMG Unified Modeling Language Specification v1.5: Revisions and recommendations, Version 1.5. Object Management Group Document formal/03-03-01, 2003.

[28] A. Saucier, Un modèle multi-vues du produit pour le développement et l'utilisation de systèmes d'aide à la conception en ingénierie mécanique, Thèse Ecole Normale Supérieure de Cachan, France, 1997.

[29] T. Soininen, and M. Stumptner. Introduction to Special Issue on Configuration. Artificial Intelligence for Engineering Design, Analysis and Manufacturing, Vol.17, Issue 1-2, 2003.

[30] S. Subbarayan and H.R. Andersen. Linear Functions for Interactive Configuration Using Join Matching and CSP Tree Decomposition. IJCAI-2005 Configuration Workshop, 2005.

[31] M. Véron. Modélisation et résolution du problème de configuration industrielle: utilisation des techniques de satisfaction de contraintes. $\mathrm{PhD}$ thesis, Institut National Polytechnique, Tarbes, November 2001.

[32] L. Yesilbas, B. Rose, M. Lombard. Specification of a repository to support collaborative knowledge exchanges in IPPOP project. Computers in Industry, Vol.57, Issue 8-9, pp.690-710.

[33] H. Zhuge : A process matching approach for flexible workflow process reuse, Information and software techology, Vol.44, pp.445-450, 2002.

[34] S. Zina, M. Lombard, L. Lossent. Integration of contextual views in configuration management for PLM applications. 9th IFAC Symposium on Automated Systems Based on Human Skill And Knowledge, 2006.

Souheïl ZINA ${ }^{1,2}$, Muriel LOMBARD ${ }^{1}$, Luc LOSSENT ${ }^{1}$, Charles HENRIOT ${ }^{2}$ E-mail: s.zina@lascom.com

${ }^{1}$ Centre de Recherche en Automatique de Nancy - UMR 7039 Université Henri Poincaré, Nancy I Faculté des Sciences - B.P. 239 54506 Vandoeuvre-lès-Nancy, France

${ }^{2}$ LASCOM

Burospace - Antélia 4, Route de Gisy 91571 Bièvres Cedex, France

Received: November 11, 2006 